\title{
Congenital heart disease, genetic syndromes, and major noncardiac malformations
}

\author{
Marta Unolt • Carolina Putotto • Dario Marino
}

Received: 6 August 2012 /Accepted: 6 September 2012 / Published online: 2 October 2012

(C) Springer-Verlag 2012

In a recent issue of your journal, we read the very interesting paper by Wren et al. [3] on mortality in infants with congenital heart disease (CHD). The authors reported that the deaths were not related to cardiovascular malformations in $33 \%$ of all patients: in $57 \%$ of infants with additional chromosomal or genetic abnormalities, in $76 \%$ of infants with major noncardiac malformations, and in only $16 \%$ of infants with isolated cardiac defects [3].

The decline of mortality occurred in all groups of patients but was marked in infants with isolated CHD [1]. Moreover, the proportion of postoperative deaths due to noncardiac cause increased from $9 \%$ in the first 10 years of the study to $29 \%$ in the second 10 years [3]. These data emphasize the role of additional noncardiac defects for the prognosis of children with CHD since these subjects with multiple and complex defects represent about one third of all CHD and can be considered one of the next challenges for pediatric cardiologists and cardiac surgeons $[1,2]$.

In analyzing mortality of patients with CHD associated with chromosomal and genetic syndromes, we must

\footnotetext{
M. Unolt $(\bowtie) \cdot$ C. Putotto $\cdot$ D. Marino

Department of Pediatrics, "La Sapienza" University,

Rome, Italy

e-mail: marta_unolt@hotmail.it

M. Unolt

Viale Regina Elena, 324,

00161 Rome, Italy
}

take into account not only the role of extracardiac malformations but also the specific cardiovascular patterns that in some occasions include peculiar additional cardiac defects that may influence cardiac surgery [1]. For this group of patients, an early and accurate multispecialistic approach is mandatory, and a careful assessment of cardiac and extracardiac risk factors can contribute to the preparation of genetic-specific diagnostic and treatment protocols [1]. Moreover, a specific follow-up targeted to cardiac and extracardiac problems is mandatory for these patients [1]. In the field of pediatric cardiology, accurate epidemiologic studies like this by Wren at al. [3] are very helpful to understand the significant role of additional genetic syndromes and major extracardiac defects in the mortality and the morbidity of children with CHD.

\section{References}

1. Formigari R, Michielon G, Digilio MC, Piacentini G, Carotti A, Giardini A, Di Donato RM, Marino B (2009) Genetic syndromes and congenital heart defects: how is surgical management affected? Eur J Cardiothorac Surg 35(4):606-614

2. Michielon G, Marino B, Oricchio G, Digilio MC, Iorio F, Filippelli S, Placidi S, Di Donato RM (2009) Impact of DEL22q11, trisomy 21, and other genetic syndromes on surgical outcome of conotruncal heart defects. J Thorac Cardiovasc Surg 138(3):565-570

3. Wren C, Irving CA, Griffiths JA, O'Sullivan JJ, Chaudhari MP, Haynes SR, Smith JH, Hamilton JR, Hasan A (2012) Mortality in infants with cardiovascular malformations. Eur J Pediatr 171 (2):281-287 